\title{
The role of Polyphenols on Gut Microbiota and ubiquitin-proteasome system in Neurodegenerative diseases
}

Hanieh Nargeh ${ }^{1}$, Fatemeh Aliabadi ${ }^{2}$, Marjan Ajami ${ }^{3 *}$, Hamidreza Pazoki -Toroudi ${ }^{2,4 *}$

${ }^{1}$ Department of Life Science Engineering, Faculty of New Sciences and Technologies, University of Tehran, Tehran, Iran

${ }^{2}$ Physiology Research Center, Faculty of Medicine, Iran University of Medical Sciences, Tehran, Iran

${ }^{3}$ Faculty of Nutrition Sciences \& Food Technology, Shahid Beheshti University of Medical Sciences

${ }^{4}$ Department of Physiology and Physiology Research Center, Faculty of Medicine, Iran University of Medical Sciences, Tehran, Iran

*Corresponding Authors:

Hamidreza Pazoki -Toroudi pazoki49@gmail.com, pazokihamidrezatoroudi95@gmail.com

Tel: +02186704547; POBox: 14515-763;

Marjan Ajami marjan.ajami80@gmail.com 


\section{PROANTHOCYANIDINS}

Proanthocyanidins, whose bioavailability is extremely dependent on the degree of polymerization, are found in wine, fruits, cereals, legumes, and chocolate (Table 1). Likewise, as compared to (-)epicatechin, proanthocyanidin dimers are more quickly absorbed, and this amount of absorption is $5-10 \%$ of (-)-epicatechin's absorption rate ${ }^{1}$. On the whole, the condensed tannins, proanthocyanidins, are polymers of flavan-3-ol (epicatechin or catechin), which are linked by means of interflavan bonds. There are two types of proanthocyanidins, namely A-type and B-type. Those proanthocyanidins linked through $\mathrm{C}_{4} \rightarrow \mathrm{C}_{8}$ or $\mathrm{C}_{4} \rightarrow \mathrm{C}_{6}$ bonds are known as $\mathrm{B}$ type proanthocyanidins, which are present in most foods, and those proanthocyanidins enjoying an extra ether bond between $\mathrm{C}_{2} \rightarrow \mathrm{O}_{7}$ are also known as A-type proanthocyanidins, which are more present in some foods such as peanuts, plum, and cranberries. Besides, proanthocyanidins that consist of (+)-catechin and (-)-epicatechin are procyanidins, which are present in pears, apples, grape seeds, and cocoa ${ }^{1}$.

As already mentioned, the degree of polymerization is a key factor to determine the molecular size of proanthocyanidins as well as its bioavailability. Monomers, dimers, trimers, and tetramers are proanthocyanidins with polymerization degree of $1,2,3$, and 4, respectively. Moreover, at the end of proanthocyanidins, there are flavan-3-ol units comprised of two aromatic rings along with a heterocyclic ring, which are identified as terminal units. Investigations indicate that the predominant proanthocyanidins in most foods such as blueberries, strawberries, grapes, sorghum, and pinto beans are polymers (> 75\% of proanthocyanidins $)^{1}$. Absorbable monomers are nearly $40 \%$ of ingested proanthocyanidins while the rest of ingested proanthocyanidins are nonabsorbable polymers with a degree of polymerization above four ${ }^{1}$. 
Regarding the bioavailability of proanthocyanidins, studies have indicated that low bioavailability of proanthocyanidins has confounded the proanthocyanidins bioactivities, since the bioavailability of proanthocyanidins is analogous with that of flavan-3-ol monomers, and most of the proanthocyanidins utilized in the bioavailability investigations are a combination of monomers, polymers, and oligomers ${ }^{1}$.

After ingestion of proanthocyanidins, the majority of them reach the colon and undergo the gut microbiota while a small number of flavan-3-ols are absorbed in the small intestine ${ }^{1}$. The microbial catabolism of proanthocyanidins by the gut microbiota is performed using a static anaerobic incubation system whereby a collection of human colonic fecal bacteria leads to the fermentation of proanthocyanidins. The efficiency of this system was elaborated in Deprez's experiment in which after $48 \mathrm{~h}$ of incubation, the entire polymeric procyanidins was degraded; the most important catabolites were 3- (3'- hydroxyphenyl) propionic acid, 3-phenyl propionic acid, 3- (4'- hydroxyphenyl) propionic acid, and 4- hydroxyphenyl acetic acid ${ }^{2}$. Regarding the catabolism of flavan-3-ol, quite a few remarkable bacterial strains such as Eubacterium oxidoreducens, Eggerthella lenta rK3, Flavonifracter plautii, Streptococcus thermophiles, Lactobacillus, and Aspergillus fumigatus have been identified ${ }^{1}$.

Due to abundant B type dimers of procyanidins in human diet, the microbial catabolism of procyanidins dimer $\mathrm{B}_{2}$ is of paramount importance. In fact, after incubation of procyanidin $\mathrm{B}_{2}$ with human gut microbiota, some microbial metabolites such as 5- (3', 4'- dihydroxyphenyl)- $\gamma$ valerolactone, 5- (3'- hydroxyphenyl)- $\gamma$-valerolactone, phenylvaleric acids, phenylpropionic acids, benzoic acid, and phenylacetic acid can be produced during several chemical processes, namely the hydroxylation of initial metabolites gained from procyanidin dimer $\mathrm{B}_{2}$, methylation of 5- (3', 
4'- dihydroxyphenyl)- $\gamma$-valerolactone, dihydroxylation of 5- (3', 4'- dihydroxyphenyl)- $\gamma-$ valerolactone, and the oxidation of aliphatic chains ${ }^{1}$.

In addition, the more the molecular size of proanthocyanidins, the less the ability of the gut microbiota to degrade proanthocyanidins. For instance, for trimers and polymers of proanthocyanidins, the production of phenolic acids by rat gut microbiota is nearly $0.7 \%$ and $0.5 \%$, respectively while for monomers and dimers, the creation of phenolic acid increases to $10 \%$ and $7 \%$, respectively ${ }^{1}$.

Regarding A-type procyanidins, a study on a pig cecum prototype investigated the microbial metabolism of procyanidin $\mathrm{A}_{2}$ and a kind of procyanidin $\mathrm{A}_{3}$ (trimer), i.e., Cinnamtannin $\mathrm{B}_{1}$. The results indicated that $40 \%$ of Cinnamtannin and $80 \%$ of procyanidin $\mathrm{A}_{2}$ were degraded during $8 \mathrm{~h}$ of incubation. The hydroxylated catabolite pattern of Cinnamtannin $\mathrm{B}_{1}$ was more complicated than that of procyanidin $\mathrm{A}_{2}$ due to the more complicated structure of Cinnamtannin $\mathrm{B}_{1}$ compared with the procyanidin $\mathrm{A}_{2}{ }^{3}$.

Studies have shown that proanthocyanidins have quite a few physiological activities. Among them, being antioxidant and being capable of preventing disease are of paramount significance ${ }^{1}$. For instance, as far as scavenging free radicals is concerned, proanthocyanidins are more efficient than resveratrol or ascorbic acid ${ }^{1}$. Investigations have indicated that if anthocyanins and proanthocyanidins are rich in some extracts, the neuroprotective impacts of those extracts can be more than that of the extracts lacking these polyphenols ${ }^{4}$. Additionally, there might be some imperfections induced by rotenone in mitochondrial respiration in dopaminergic cells, which can be improved by some extracts from grape seed and blueberry rich in anthocyanins and proanthocyanidins ${ }^{4}$. Also, microglial cells can undergo the LPS and release the nitrite; this nitrite release can be reduced using a purple basal extract ${ }^{4}$. Therefore, anthocyanins and 
proanthocyanidins can boost the mitochondrial function, thereby improving the neurodegeneration in $\mathrm{PD}^{4}$.

As to the antioxidant ability in microbial metabolites of proanthocyanidins, it should be noted that 5- (3', 4'- dihydroxyphenyl)- $\gamma$-valerolactone as compared to (-)-epicatechin and Lascorbic acid has lower antioxidant capability and higher antioxidant capacity, respectively ${ }^{5}$. Likewise, the microbial metabolites of proanthocyanidins can have a considerable importance in atheroprotection as well as chemoprevention in vivo owing to the decrease in the level of cyclooxygenase-2 in a colonic HT-29 cell line (human colorectal adenocarcinoma cell line) ${ }^{6}$. 


\begin{tabular}{|c|c|c|c|c|c|c|c|c|c|c|}
\hline Polyphenol group & Examples & Main structure & Sources & $\begin{array}{l}\text { Pathway of } \\
\text { action }\end{array}$ & Effects & $\begin{array}{l}\text { Special } \\
\text { disease }\end{array}$ & $\begin{array}{l}\text { Microbial } \\
\text { metabolites }\end{array}$ & $\begin{array}{l}\text { Model } \\
\text { of } \\
\text { study }\end{array}$ & Clinical trial & $\operatorname{Ref}$ \\
\hline Proanthocyanidin & $\begin{array}{l}\text { Procyanidin, } \\
\text { Prodelphinidin, } \\
\text { Propelargonidin, } \\
\text { Profisetinidin, } \\
\text { Proguibourtinidin } \\
\text {,Prorobinetinidin, } \\
\text { Proapigenidin, } \\
\text { Proluteolinidin, } \\
\text { Procassinidin, } \\
\text { Probutinidins, } \\
\text { Protricetinidin, } \\
\text { Proteracacinidin, } \\
\text { Promelacacinidin }\end{array}$ & & $\begin{array}{l}\text { Wine, } \\
\text { Fruits, } \\
\text { Cereals, } \\
\text { Legumes, } \\
\text { and } \\
\text { Chocolate }\end{array}$ & $\begin{array}{l}\text { Blocking the } \\
\text { activation of } \\
\text { the } \\
\text { mitochondri } \\
\text { al apoptosis } \\
\text { pathway }\end{array}$ & $\begin{array}{l}\text { Reduced } \\
\text { A } \beta \\
\text { peptide } \\
\text { oligomer } \\
\text { ization } \\
\text { and fibril } \\
\text { develop } \\
\text { ment, } \\
\text { Suppress } \\
\text { the } \\
\text { neurotoxi } \\
\text { c effects } \\
\text { of } \\
\text { rotenone } \\
\text { in a } \\
\text { primary } \\
\text { cell } \\
\text { culture } \\
\text { model of } \\
\text { PD }\end{array}$ & $\begin{array}{l}\mathrm{PD} \text { and } \\
\mathrm{AD}\end{array}$ & $\begin{array}{l}\text { 5- (3', 4'- } \\
\text { dihydroxyp } \\
\text { henyl)- } \gamma- \\
\text { valerolacto } \\
\text { ne, 5- (3'- } \\
\text { hydroxyphe } \\
\text { nyl)- } \gamma- \\
\text { valerolacto } \\
\text { ne, } \\
\text { phenylvaler } \\
\text { ic acids, } \\
\text { phenylpropi } \\
\text { onic acids, } \\
\text { benzoic } \\
\text { acid, and } \\
\text { phenylaceti } \\
\text { c acid }\end{array}$ & $\begin{array}{l}\text { Cell } \\
\text { culture }\end{array}$ & $\begin{array}{l}\text { Not reported } \\
\text { yet. }\end{array}$ & $\begin{array}{l}1,4, \\
6,7\end{array}$ \\
\hline
\end{tabular}





\section{References}

1. Ou, K.; Gu, L., Absorption and metabolism of proanthocyanidins. Journal of Functional Foods 2014, 7, 43-53.

2. Déprez, S. p.; Brezillon, C.; Rabot, S.; Philippe, C.; Mila, I.; Lapierre, C.; Scalbert, A., Polymeric proanthocyanidins are catabolized by human colonic microflora into low-molecular-weight phenolic acids. The Journal of nutrition 2000, 130 (11), 2733-2738.

3. Engemann, A.; Hübner, F.; Rzeppa, S.; Humpf, H.-U., Intestinal metabolism of two A-type procyanidins using the pig cecum model: detailed structure elucidation of unknown catabolites with Fourier transform mass spectrometry (FTMS). Journal of agricultural and food chemistry 2012, 60 (3), 749757.

4. Strathearn, K. E.; Yousef, G. G.; Grace, M. H.; Roy, S. L.; Tambe, M. A.; Ferruzzi, M .G.; Wu, Q.-L.; Simon, J. E.; Lila, M. A.; Rochet, J.-C., Neuroprotective effects of anthocyanin-and proanthocyanidin-rich extracts in cellular models of Parkinson 's disease. Brain research 2014, 1555, 60-77.

5. Unno, T.; Tamemoto, K.; Yayabe, F.; Kakuda ,T., Urinary excretion of 5-(3 ', 4 '-dihydroxyphenyl)$\mathrm{Y}$-valerolactone, a ring-fission metabolite of (-)-epicatechin, in rats and its in vitro antioxidant activity. Journal of agricultural and food chemistry 2003, 51 (23), 6893-6898.

6. Karlsson, P. C.; Huss, U.; Jenner, A.; Halliwell, B.; Bohlin, L.; Rafter, J. J., Human fecal water inhibits COX-2 in colonic HT-29 cells: role of phenolic compounds. The Journal of nutrition 2005, 135 (10), 23432349.

7. Luca, S. V.; Bujor, A.; Miron, A.; Aprotosoaie, A. C ;.Skalicka-Woźniak, K.; Trifan, A., Preparative separation and bioactivity of oligomeric proanthocyanidins. Phytochemistry Reviews 2020, 19 (5), 10931140. 